\title{
MEDIÇÃO DO COEFICIENTE DE ATRITO DO CONJUNTO DE EMBREAGEM EM DINAMÔMETRO CONVENCIONAL
}

\author{
Thomaz Ernesto de Sousa Savio ${ }^{1.2}$, Egidio Guerreiro ${ }^{3}$, Felipe Sahade $^{2}$, Ailton Soares ${ }^{3}$ \\ ${ }^{1}$ ITA - Instituto Tecnológico de Aeronáutica \\ ${ }^{2}$ Ford Motor Company \\ ${ }^{3}$ SENAI CIMATEC \\ E-mails: tsavio@ford.com, tsavio47@gmail.com, egidio.guerreiro@fieb.org.br, \\ fsahade@ford.com,ailtonsj@fieb.org.br
}

\section{RESUMO}

Este estudo propõe um método eficiente para medição dinâmica do coeficiente de atrito do conjunto de embreagem ao longo do tempo exposto a ciclos padrões de embreamento. $\mathrm{O}$ método utiliza um dinamômetro passivo para controlar a rotação do eixo de saída do conjunto de embreagem enquanto o motor é controlado pela ECU, existindo também um sistema de acionamento de embreagem para controlar o desacoplamento. Neste trabalho é demonstrado o efeito da presença de líquido anticorrosivo com base de água no coeficiente de atrito do conjunto ao longo dos ciclos de acionamento de forma quantitativa. $\mathrm{O}$ resultado deste trabalho mostra um método para medição de coeficiente de atrito com alta repetibilidade sem requerer instalações especiais para teste de embreagem.

\section{INTRODUÇÃO}

A aplicação de fluido anticorrosivo é uma prática comum na indústria automotiva principalmente em regiões com alta salinidade - para assegurar integridade física da peça durante o período de armazenamento em que possa ser submetida.

Trata-se de um fluido não-inflamável, solúvel em água e de baixa viscosidade, que pode ser aplicado por pulverização, imersão, pintura ou rolo, com a temperatura do banho variando de temperatura ambiente à $50^{\circ} \mathrm{C}$. O tempo de proteção depende da concentração utilizada. Ele pode ser utilizado adicionando diretamente à água, o que evita a formação de emulsões invertidas. Em geral, sua concentração é de 5,0\% a 12,0\% volume. Outros benefícios indicados pelos diversos fabricantes são:

- Quando diluído em água, o produto forma uma emulsão meta estável, depositando um filme uniforme, ideal para superfícies metálicas de brilho;

- O filme depositado pelo produto é praticamente indiscernível, facilitando seu manuseio, inspeção e embalagem;

- Quando aplicado a quente facilita a evaporação da água e a formação de protetor de filme;

No entanto, em estudos preliminares, foi identificado que a depender da composição química do fluido e da quantidade aplicada à peça (assumindo excesso), o mesmo poderá influenciar na 
acoplagem do conjunto volante e embreagem, causando "escorregamento" do sistema quando acionado e em baixa rotação, decorrente da redução do coeficiente de atrito.

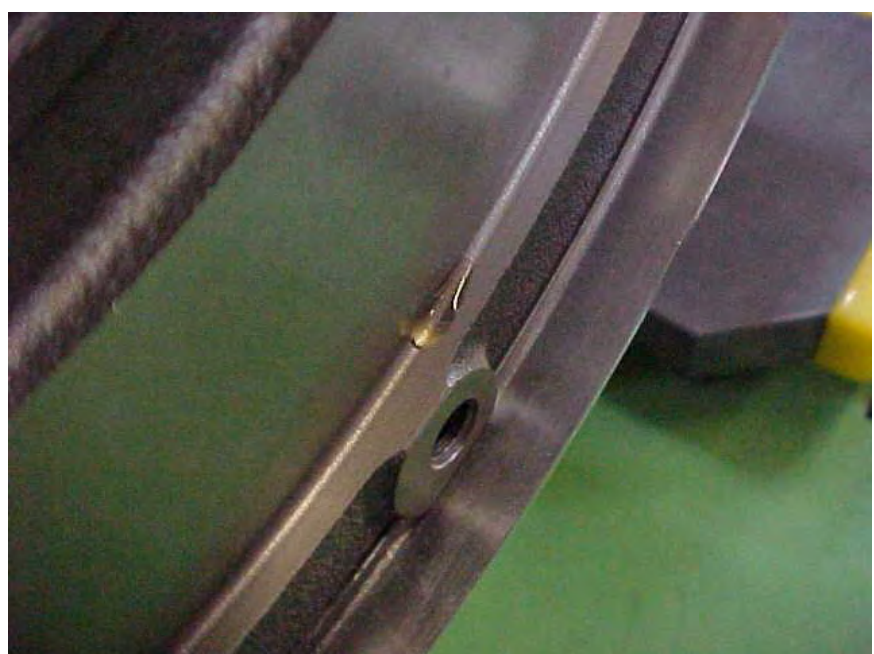

Figura 1: Exemplo de componente rejeitado por apresentar excess de fluido anticorrosivo

Desta forma, surgiu a necessidade de mensurarmos o impacto no coeficiente de atrito do conjunto de embreagem e volante automotivos após aplicação do uso de fluidos anticorrosivos de modo à identificarmos qualquer efeito negativo proveniente do mesmo.

\section{FUNDAMENTAÇÃO TEÓRICA}

Mensurar o coeficiente de atrito de um conjunto de embreagem automotivo dinamicamente pode ser complexo e exigir aparatos especiais de uso único, o que comumente aumenta o custo e o tempo de projeto destes componentes e suas aplicações. Em essência, sistemas de atrito são processos que envolvem aumento de entropia total devido a irreversibilidades, o que reflete em variações intrínsecas a cada acionamento. O Uso de simulações para estudar o comportamento de conjuntos de atrito em diferentes regimes operacionais acelera o desenvolvimento destes sistemas [1], porém é necessário o teste físico para calibrar os modelos de CAE e validar os resultados. Uma forma de estudar os fenômenos de atrito destes conjuntos consiste em elaborar modelos físicos simplificados e versáteis [2], no entanto esta estratégia pode incorrer em dificuldades operacionais quando se necessita avaliar o efeito de contaminantes na operação do conjunto quando operando no sistema completo.

Este trabalho estuda os efeitos do banho anticorrosivo a base de água no coeficiente de atrito em um conjunto de embreagem para aplicações automotivas, a estratégia aqui utilizada consiste em reproduzir o modo de operação do conjunto de forma padronizada e utilizando os componentes anterior e posterior (motor e caixa de câmbio respectivamente) idênticos aos do regime de trabalho final, evitando assim qualquer tipo de ruído parasita que possa vir de adaptações destas interfaces.

Para o equacionamento do fenômeno usa-se o teorema dos Pis de Buckingham para conjuntos de atrito do tipo embreagem proposto por Shigley (2005)[3], onde:

$$
\pi_{1}=\frac{T}{F \cdot D}
$$




$$
\begin{aligned}
& \pi_{2}=f \\
& \pi_{3}=\frac{d}{D}
\end{aligned}
$$

Sendo:

$T=$ Torque transmitido pelo conjunto [N.m];

$F=$ Força normal aplicada ao disco $[\mathrm{N}]$;

$D=$ diâmetro externo do disco $[\mathrm{m}]$;

$f=$ coeficiente de atrito do material do disco [ ];

$d=$ diâmetro menor do disco $[\mathrm{m}]$;

Em (1) temos o adimensional de carga, em (2) o coeficiente de atrito e em (3) temos a razão geométrica do sistema. Com algumas manipulações algébricas podemos concluir que o coeficiente de atrito do conjunto é dado por:

$$
f=3 \cdot \pi_{1} \cdot\left(\frac{1-\pi_{3}{ }^{2}}{1-\pi_{3}{ }^{3}}\right)
$$

A potência de acionamento pode ser descrita como:

$$
p=T \cdot \dot{\theta}
$$

Onde:

$p=$ potência instantânea de acoplamento;

$\dot{\theta}=$ escorregamento do conjunto; sendo:

Integrando (5) ao longo do tempo obtemos a energia total do ciclo de acionamento,

$$
E=\int_{0}^{t} p \cdot d t
$$

Com este equacionamento é possível analisar a evolução do coeficiente de atrito do conjunto ao longo de uma série de acionamentos.

\section{APARATO EXPERIMENTAL}

Para inicio dos experimentos foi preciso mensurar a força normal aplicada pelo conjunto platô e disco de embreagem no volante do motor. Para tal, foi montada uma bancada contendo os seguintes itens:

- Caixa de câmbio

- Volante do motor

- Conjunto platô / disco de embreagem

- Atuador de embreagem 
- Pedal de embreagem

- Atuador hidráulico

- Atuador elétrico

$\mathrm{O}$ volante do motor teve $4 \mathrm{~mm}$ de sua face de contato com o disco de embreagem usinados para permitir que o atuador hidráulico aplicasse os esforços necessários para medição da força Normal. O conjunto foi montado de forma equivalente a sua montagem no veículo e o disco de embreagem foi ligado a uma célula de carga e atuador hidráulico de forma que fosse possível à variação da compressão sobre o platô e a medição dos esforços relacionados.

A linha de acionamento hidráulico do atuador de embreagem e o pedal de embreagem foram instrumentados para medir a pressão e a posição do pedal durante os ciclos de ensaio. Um atuador elétrico foi ligado ao pedal para acionamento da embreagem, o sistema é mostrado na figura 2.

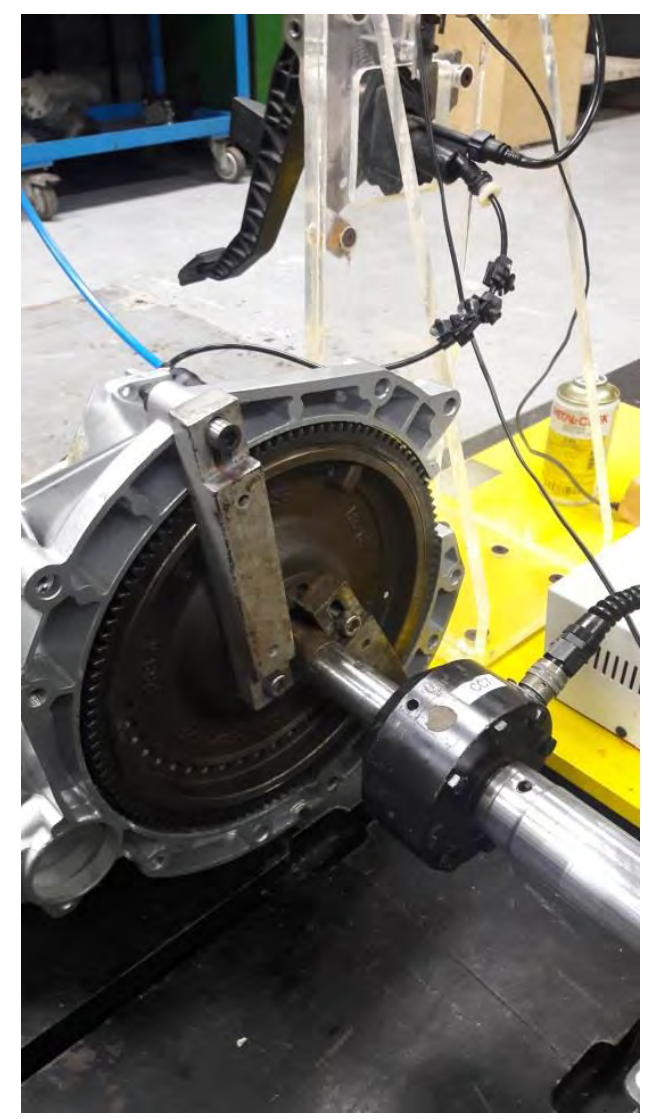

Figura 2: Aparato de medição de força normal no platô

Para medição da força normal, inicialmente o atuador hidráulico foi avançado em $4 \mathrm{~mm}$ em direção a caixa de câmbio de forma a compensar a usinagem realizada e submeter o conjunto à ação da mola do platô. Com o auxilio do atuador elétrico foram aplicados ciclos de acionamento da embreagem, variando de 0 a 100\%, com rampas de 1, 2 e 3s. Os valores de Força, Pressão e posição do pedal observados foram aquisitados e devido a histerese, o melhor fator para correlacionar a força normal na embreagem é a posição do pedal. A figura 3 mostra os valores medidos e a equação de correlação polinomial de terceira ordem. 


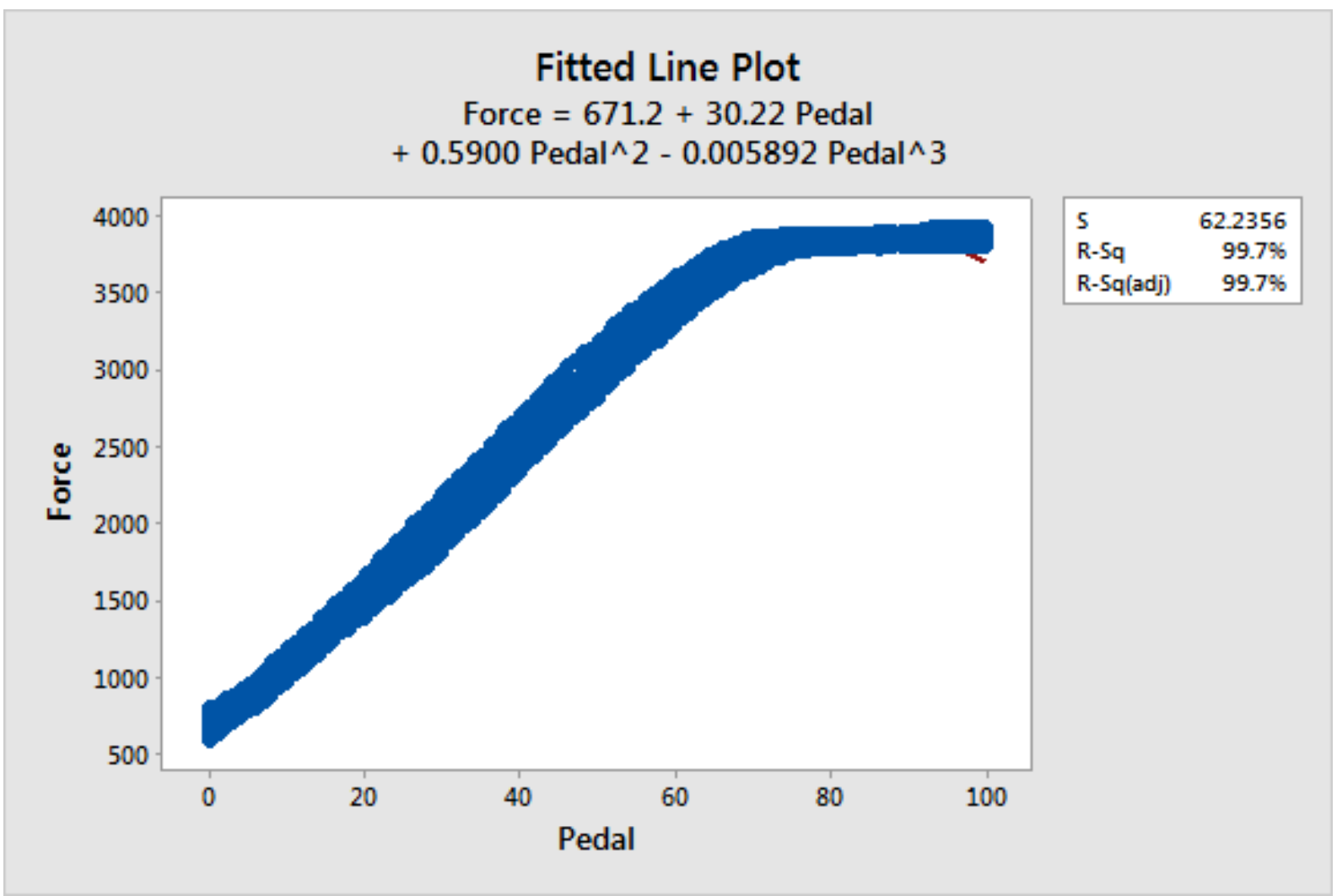

Figura 3: Correlação de força normal do platô e posição do pedal de embreagem.

O ciclo padrão de embreamento é mostrado na figura 4. O motor é ajustado para manter a borboleta totamente aberta (WOT) e como rotação limitada eletronicamente em 4000 revoluções por minuto (rpm), o dinamômetro é controlado para manter a rotação em 1000 rpm.O ciclo se inicia com o conjunto acoplado em $1000 \mathrm{rpm}$ com motor em WOT, então se aciona o pedal de embreagem até o fim de curso, desacoplando assim o conjunto, para então refazer o acoplamento de forma linear em 30 segundos.

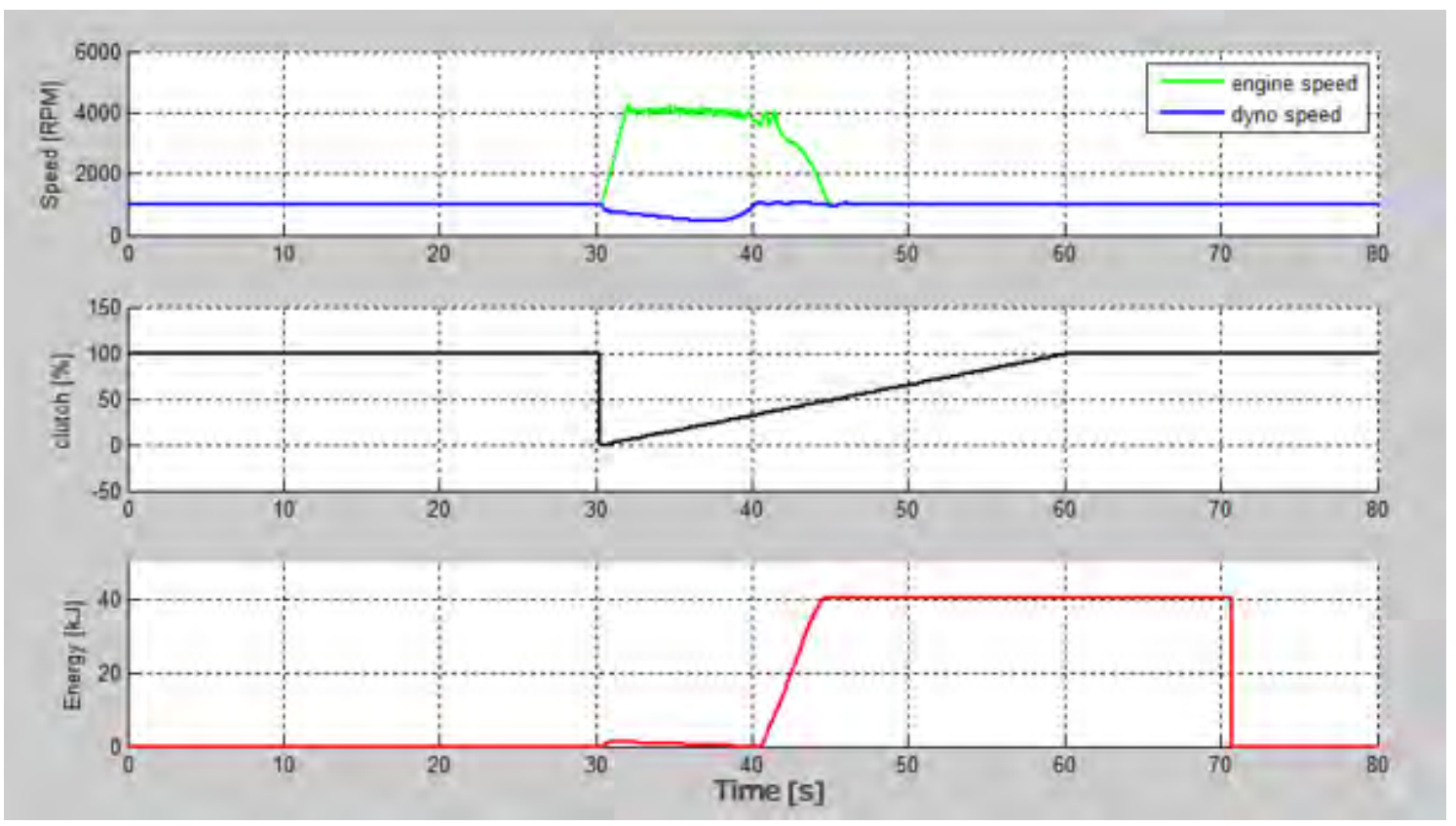

Figura 4: Rotação, posição de pedal de embreagem e energia de acoplamento de um ciclo. 
A energia dissipada em um acoplamento deve estar entre 35 e $45 \mathrm{~kJ}$ para que o embreamento seja representativo com o uso normal.

Para o cálculo do coeficiente de atrito de cada ciclo foi utilizada a estratégia de analisar os dados apenas na janela de contato com deslizamento. A figura 5 mostra o momento de acionamento e a janela de contato. A janela de contato se inicia quando o torque transmitido ultrapassa os 40 N.m e se encerra quando a diferença de rotação for menor que $100 \mathrm{rpm}$.
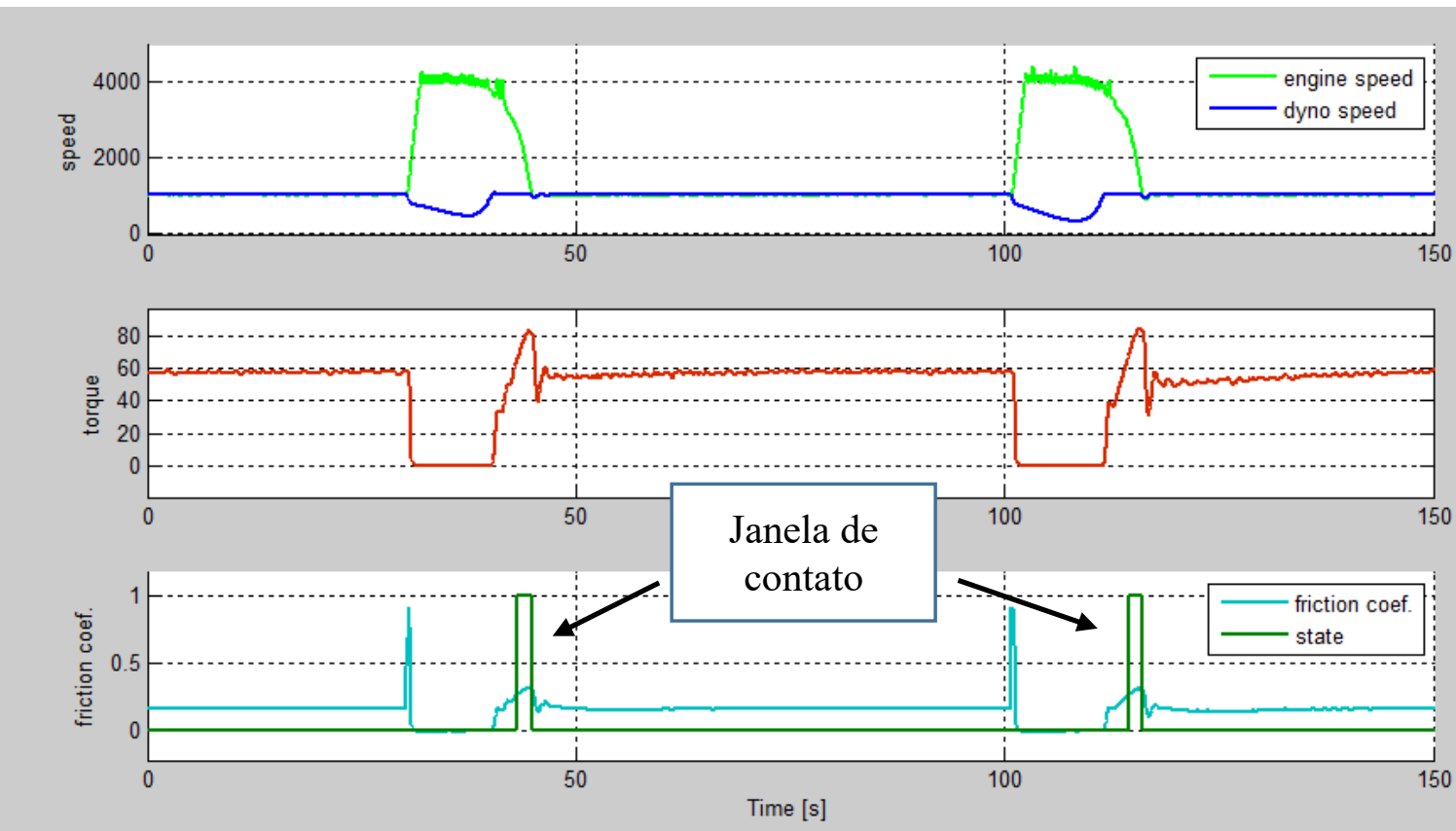

Figura 5: Rotação, torque, coeficiente de atrito e janela de contato no ciclo de embreamento.

O coeficiente de atrito de cada ciclo considerado é a média do valor calculado dentro da janela de contato.

\section{RESULTADOS}

Foram realizados 400 ciclos de embreamento, com 3 amostras de cada tipo analisadas, isto é, 3 conjuntos com anticorrosivo e 3 conjuntos totalmente secos, os resultados obtidos são mostrados na figura 6 . 


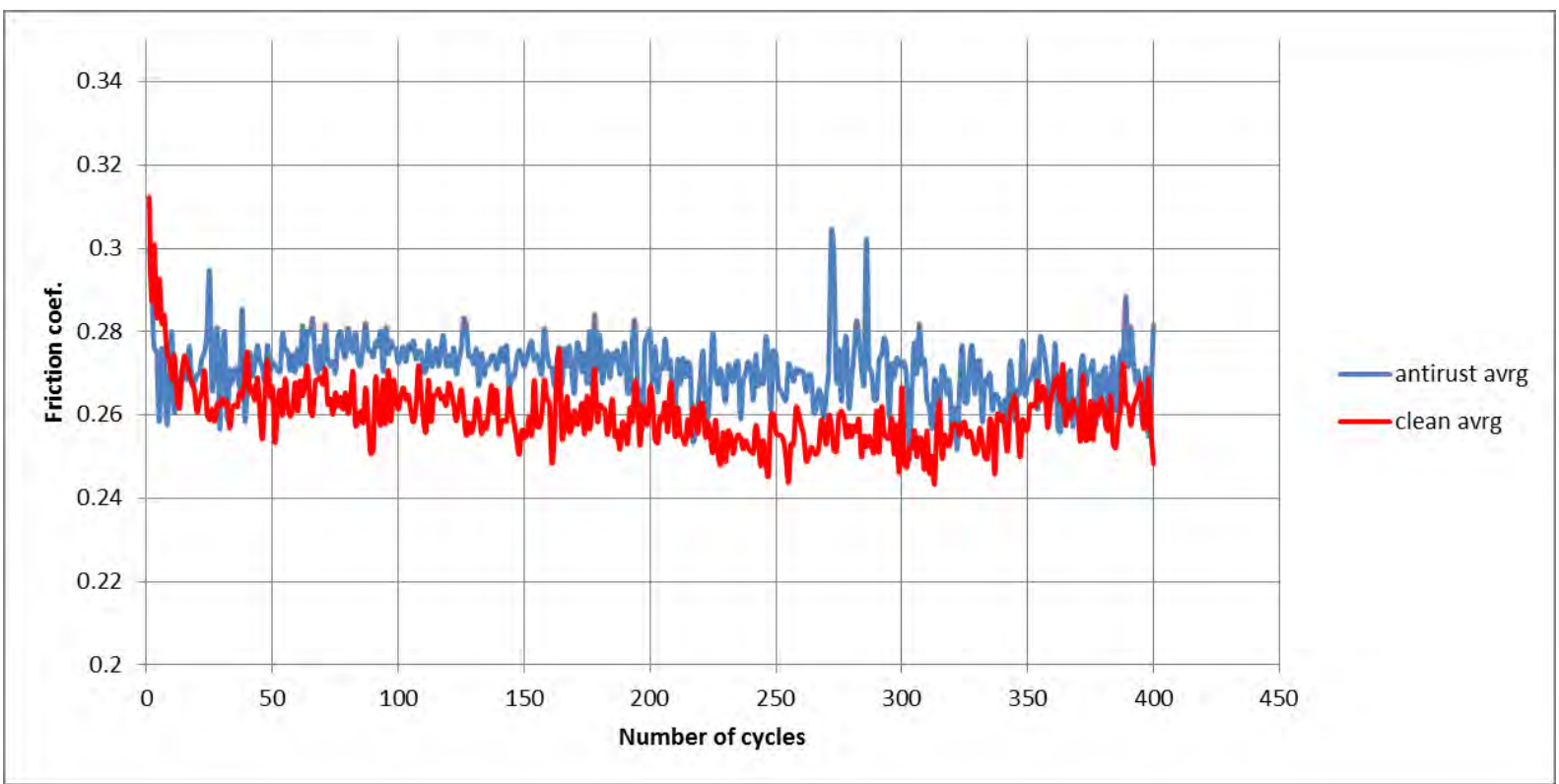

Figura 6: Coeficiente de atrito das duas configurações ao longo dos ciclos de acionamento.

Os resultados mostram que a ausência do banho anticorrosivo só é percebida nos 10 primeiros ciclos, onde o coeficiente de atrito do conjunto seco é maior. A partir do $10^{\circ}$ ciclo o conjunto que recebeu banho anticorrosivo mostra coeficente de atrito igual ou maior em relação ao conjunto seco.

Nos conjuntos de mesma configuração analisados o resultado observado foi bastante similar para as 3 amostras, com flutuação média inferior a 1\% no coeficiente de atrito médio.

\section{CONCLUSÃO}

A diferença observada no coeficiente de atrito nas duas configurações de conjuntos é considerada pequena e portanto dificilmente poderia ser percebida numa análise subjetiva apenas dirigindo o veículo. Durante o manuseio do carro dentro da linha de montagem até o deslocamento ao pátio de estoque e envio para a concessionária são realizados cerca de 40 acionamentos de embreagem, o que torna a diferença de coeficiente de atrito no conjunto nos 10 primeiros acionamentos transparente para o cliente final.

O método de medição dinâmica de coeficiente de atrito proposto para este trabalho se mostrou eficiente dado a repetibilidade do resultados e cumpriu o objetivo de não requerer nenhum equipamento de uso exclusivo para o ensaio.

\section{AGRADECIMENTOS}

Os Autores agradecem a FORD MOTOR COMPANY do Brasil e ao Laboratório de motores SENAI CIMATEC pela contribuição neste trabalho.

\section{REFERÊNCIAS}


[1] Petrun, T., Flasker, J., Kegl, M. 2012, A Friction model for dynamic analyses of multibody systems with a fully functional friction clutch, DOI10.1177/1464419312464708.

[2] Marklund, P., Larsson, R. 2008, Wet clutch friction characteristics obtained from simplified pin on disc test, Lulea, SE-97187, Sweden.

[3] SHIGLEY, J. E., MISCHKE, C. E., BUNDYNAS, R. G. Projeto de Engenharia Mecânica.

$7^{\mathrm{a}}$. Edição, Bookman, ISBN 978-85-363-0562-2, 2005 